\title{
Measuring emotions in students' learning and performance: The Achievement Emotions Questionnaire (AEQ)
}

\author{
Reinhard Pekrun ${ }^{\mathrm{a}, *}$, Thomas Goetz ${ }^{\mathrm{b}, \mathrm{c}}$, Anne C. Frenzel ${ }^{\mathrm{d}}$, Petra Barchfeld ${ }^{\mathrm{a}}$, Raymond P. Perry ${ }^{\mathrm{e}}$ \\ ${ }^{a}$ Department of Psychology, University of Munich, Munich, Germany \\ ${ }^{b}$ Department of Education, University of Konstanz, Konstanz, Germany \\ ${ }^{\mathrm{C}}$ Department of Education, Thurgau University of Teacher Education, Thurgau, Switzerland \\ ${ }^{\mathrm{d}}$ Department of Psychology, University of Augsburg, Augsburg, Germany \\ ${ }^{\mathrm{e}}$ Department of Psychology, University of Manitoba, Winnipeg, Manitoba, Canada
}

Keywords:

Achievement emotion

Pride

Anger

Boredom

Test anxiety

Self-regulated learning

Control-value theory

\begin{abstract}
A B S T R A C T
Aside from test anxiety scales, measurement instruments assessing students' achievement emotions are largely lacking. This article reports on the construction, reliability, internal validity, and external validity of the Achievement Emotions Questionnaire (AEQ) which is designed to assess various achievement emo tions experienced by students in academic settings. The instrument contains 24 scales measuring enjoy ment, hope, pride, relief, anger, anxiety, shame, hopelessness, and boredom during class, while studying and when taking tests and exams. Scale construction used a rational empirical strategy based on Pek run's (2006) control value theory of achievement emotions and prior exploratory research. The instru ment was tested in a study using a sample of university students ( $N$ 389). Findings indicate that the scales are reliable, internally valid as demonstrated by confirmatory factor analysis, and externally valid in terms of relationships with students' control value appraisals, learning, and academic performance. The results provide further support for the control value theory and help to elucidate the structure and role of emotions in educational settings. Directions for future research and implications for educa tional practice are discussed.
\end{abstract}

\section{Introduction}

Academic settings abound with achievement emotions such as enjoyment of learning, hope, pride, anger, anxiety, shame, hope lessness, or boredom. These emotions are critically important for students' motivation, learning, performance, identity development, and health (Schutz \& Pekrun, 2007). Accordingly, theoretically grounded measurement instruments are needed to analyze their functions and origins, and to assess these emotions in educational practice. To date, there is a lack of such instruments, with the sin gle exception of test anxiety questionnaires. In response to this deficit, we developed a self report instrument measuring various achievement emotions that students commonly experience in aca demic settings (Achievement Emotions Questionnaire, AEQ). Previ ous publications referring to this instrument have reported data using preliminary versions or selected scales only (Acee et al., 2010; Daniels et al., 2009; Mouratidis, Vansteenkiste, Lens, \& Auweele, 2009; Pekrun, Elliot, \& Maier, 2006, 2009; Pekrun, Goetz, Daniels, Stupnisky, \& Perry, 2010; Pekrun, Goetz, Perry, Kramer, \&

* Corresponding author. Address: Department of Psychology, University of Munich, Leopoldstrasse 13, 80802 Munich, Germany.

E-mail address: pekrun@Imu.de (R. Pekrun).
Hochstadt, 2004). The present research involves the first compre hensive investigation of the AEQ including all scales of the instru ment within one analysis. This investigation makes it possible to examine the psychometric quality of the instrument, to analyze the overall structure and role of achievement emotions as experi enced by students in academic settings, and to further test hypoth eses of the control value theory of achievement emotions (Pekrun, 2006; Pekrun, Frenzel, Goetz, \& Perry, 2007).

Construction of the AEQ was informed by the models for assess ing achievement emotions that are provided by the measurement of test anxiety. Specifically, whereas early instruments such as the Test Anxiety Questionnaiore (TAQ; Mandler \& Sarason, 1952) deemed test anxiety to be a unidimensional construct, conceptions developed since then make it possible to differentiate various com ponents of the construct, with affective, cognitive, and physiologi cal components being central to contemporary measures (Zeidner, 2007). The advances in the measurement of test anxiety enabled researchers to successfully uncover the structures, functions, and origins of this emotion (for overviews, see Hembree, 1988; Zeidner, 1998, 2007)

In line with current test anxiety measurement and conceptions of emotion more generally, the AEQ is based on a multi component definition of achievement emotion. In contrast to test anxiety 
measures, however, the AEQ assesses a broader range of major achievement emotions. The 24 scales of the instrument tap into nine different emotions occurring in three different academic achievement settings. In the following sections, we first outline the theoretical conception underlying the $\mathrm{AEQ}$ and its validation. Next, we describe the construction of the instrument. We then report an empirical analysis targeting item and scale statistics, reliability, internal validity, and external validity of the instrument.

\subsection{Conceptual framework: the control value theory of achievement emotions}

As a framework for defining emotions, constructing scales, and validating the instrument, the control value theory of achievement emotions was used (Pekrun, 2006; Pekrun et al., 2007). The con trol value theory provides an integrative approach for analyzing various emotions experienced in achievement contexts, including academic settings as well as achievement situations in other life domains (e.g., sports, professional activities). The theory builds on assumptions from expectancy value theories of emotions (Pek run, 1992a; Turner \& Schallert, 2001), transactional approaches (Lazarus \& Folkman, 1984), attributional theories (Weiner, 1985), and models of the performance effects of emotions (Fredrickson, 2001; Pekrun, 1992b; Pekrun, Goetz, Titz, \& Perry, 2002; Zeidner, $1998,2007)$. It expands these views by integrating propositions from different theories and by focusing on both outcome related and activity related achievement emotions.

\subsubsection{Definition and component structures of emotion}

In line with contemporary component process models of emo tions (Scherer, 2009), the control value theory views emotions as sets of interrelated psychological processes, whereby affective, cognitive, motivational, and physiological components are of pri mary importance. For example, anxiety can comprise uneasy and tense feelings (affective), worries (cognitive), impulses to escape from the situation (motivational), and peripheral activation (phys iological). This view is consistent with leading edge conceptions of test anxiety, but extends these conceptions in an important way. Although most current test anxiety instruments assess affective, physiological, and cognitive components of anxiety, they neglect the motivational component. Items pertaining to this component were originally part of Mandler and Sarason's (1952) TAQ but later motivational components were omitted. These components are in cluded in the current conception.

From a measurement perspective, the multi component concep tion of emotions adopted in the control value theory implies that emotions are best modeled as hierarchically organized structures, with the components comprising an emotion being first order factors and the emotion itself being represented by a second order factor. For example, test anxiety would be conceived as being repre sented by one second order factor for the emotion test anxiety, and four primary factors for the affective, cognitive, motivational, and physiological components of test anxiety that are nested within the second order factor (Fig. 1; see Hodapp \& Benson (1997) for a similar approach). Empirically, such hierarchical factor models should prove superior to single factor models postulating just one factor representing the emotion.

\subsubsection{Definition of achievement emotion}

Achievement emotions are defined as emotions that are directly linked to achievement activities or achievement outcomes. In past research, studies on achievement emotions focused on emotions related to achievement outcomes, including both prospective out come emotions, such as hope and anxiety linked to possible success and failure, respectively, and retrospective outcome emotions like pride and shame linked to prior success and failure, respectively
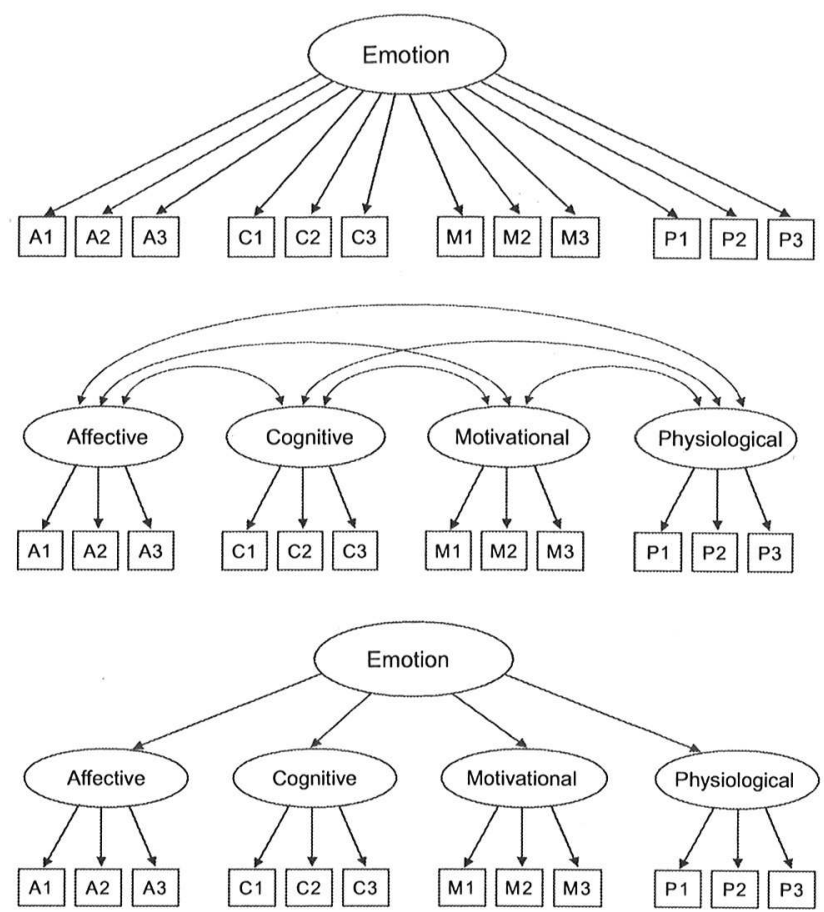

Fig. 1. Models for component structures of achievement emotions. Upper part: Model $1 \mathrm{~A}$ (one-factor model). Middle part: Model $1 \mathrm{~B}$ (four component factors model). Lower part: Model 1C (hierarchical model). A1-A3, C1-C3, M1-M3, P1-P3 denote affective, cognitive, motivational, and physiological items, respectively.

(Weiner, 1985; Zeidner, 1998). The definition proposed by the con trol value theory implies that activity emotions pertaining to cur rent achievement related activities are also considered as achievement emotions. Examples are students' enjoyment of learning, boredom experienced during classroom instruction, or anger at the task demands of academic learning (Pekrun, 2006; Pekrun et al., 2010).

In Pekrun's (2006; Pekrun et al., 2002) three dimensional tax onomy of achievement emotions, the differentiation of activity versus outcome emotions pertains to the object focus of these emotions. In addition, as with emotions more generally, achieve ment emotions can be grouped according to their valence and to the degree of activation implied. In terms of valence, positive emotions can be distinguished from negative emotions, such as pleasant enjoyment versus unpleasant anxiety. In terms of activa tion, physiologically activating emotions can be differentiated from deactivating emotions, such as activating hope versus deac tivating hopelessness. By using the dimensions valence and acti vation, the taxonomy is consistent with circumplex models of affect that arrange affective states in a two dimensional (valence $\times$ activation) space (Feldman Barrett \& Russell, 1998; Linnenbrink, 2007).

\subsubsection{Situational context and temporal specificity}

Achievement emotions occur in different academic settings, such as attending class, studying, and taking tests and exams These settings differ in relation to their functions and social struc tures. By implication, emotions can vary across these settings as well. For example, enjoyment of classroom instruction may be dif ferent from enjoying the challenge of an exam some students may be excited when going to class, others when writing exams. There fore, measures of achievement emotions should distinguish be tween emotions experienced in these different settings. 
In addition, in keeping with emotions more generally, achieve ment emotions can be conceptualized in trait like or state like ways. The defining characteristic of the trait versus state distinc tion is the temporal generality of the emotion under consideration. For example, habitual test anxiety as measured by test anxiety scales is regarded as a trait emotion (Zeidner, 1998); anxiety expe rienced an hour before a specific exam would be viewed as a state emotion (Spielberger, Anton, \& Bedell, 1976); and emotions typi cally experienced by a student in a specific semester long course over a lengthy period of time would be located in between trait and state emotions on a conceptual continuum representing emo tional traits versus states.

\subsubsection{Antecedents of achievement emotions}

The control value theory posits that achievement emotions are induced when the individual feels in control of, or out of control of, activities and outcomes that are subjectively important implying that appraisals of control and value are the proximal determinants of these emotions. Control appraisals pertain to the perceived con trollability of achievement related actions and outcomes. As such, two important types of control appraisals are action control expec tancies and action outcome expectancies (see Skinner's (1996) taxonomy of constructs of control). Action control expectancies are expectancies that an action can be initiated and performed by the individual (Pekrun, 2006), with "self efficacy expectation" (Bandura, 1977) being the modal term used most often today to denote these expectancies. Action outcome expectancies imply that one's actions (e.g., academic effort) will produce desired out comes (e.g., good grades); in the educational literature, these expectancies have been called "academic control" (e.g., Perry, Hladkyj, Pekrun, \& Pelletier, 2001). Value appraisals relate to the subjective importance of achievement related activities and outcomes.

The theory proposes that enjoyment of achievement activities is instigated when these activities are experienced as both controlla ble and valuable. For example, a student is expected to enjoy studying when she feels competent to master the learning material and perceives the material as interesting. Conversely, boredom is induced when the activity lacks any incentive value. The anticipa tory outcome emotions hope and anxiety, related to potential suc cess and failure, respectively, are thought to arise when there is some lack of control, implying uncertainty about these achieve ment outcomes, paired with subjective importance of these out comes. For example, a student would feel anxious before an exam if he expects that he could fail and perceives the exam as important. If he is sure to succeed or does not care, there is no need to be anxious. Hopelessness is thought to be triggered when achievement seems not controllable at all, implying subjective cer tainty about failure. Finally, retrospective outcome emotions such as pride and shame are induced when success and failure, respec tively, are perceived to be caused by internal factors implying con trol, or lack of control, about these outcomes (for further details, see Pekrun, 2006).

\subsubsection{Outcomes of achievement emotions}

According to the control value theory, achievement emotions can profoundly affect students' learning and performance. Several mediating mechanisms are posited to be responsible for these ef fects, including students' motivation, strategy use, and regulation of learning (Pekrun, 1992b, 2006). Emotions are thought to influ ence students' intrinsic motivation to learn which is based on interest and curiosity in learning, as well as their extrinsic motiva tion related to the attainment of positive outcomes (e.g., good grades) or to the prevention of negative outcomes (e.g., poor grades). Furthermore, emotions are expected to facilitate use of dif ferent learning strategies, including flexible strategies such as elab oration of learning material as well as rigid strategies such as simple rehearsal. In addition, emotions can promote different styles of regulation including students' self regulation versus external regulation of learning.

Positive activating emotions such as enjoyment, hope, and pride are thought to promote both intrinsic and extrinsic motivation, facilitate use of flexible learning strategies, and support self regu lation, thus positively affecting academic performance under most conditions. Conversely, negative deactivating emotions, such as hopelessness and boredom, are posited to uniformly reduce moti vation and the effortful processing of information, implying nega tive effects on performance. For positive deactivating and negative activating emotions, such as relief, anger, anxiety, and shame, the relationships are presumed to be more complex. Specifically, an ger, anxiety, and shame can undermine intrinsic motivation, but can induce strong extrinsic motivation to invest effort to avoid fail ure, implying that the effects on students' overall motivation to learn and invest effort need not be negative. Furthermore, these emotions are expected to promote use of more rigid learning strat egies like rehearsal. As a consequence, negative activating emo tions can have variable effects on students' learning (also see Lane, Whyte, Terry, \& Nevill, 2005; Turner \& Schallert, 2001) although negative effects on overall academic performance likely outweigh any beneficial consequences for most students (Boeka erts, 1993; Hembree, 1988; Pekrun, 2006).

\subsection{Construction of the $A E Q$}

\subsubsection{Rational empirical strategy of test construction}

Construction of the AEQ was based on the theoretical consider ations outlined earlier and on a series of preliminary empirical studies. These studies included exploratory investigations analyz ing the occurrence and structures of various achievement emotions (Pekrun, 1992c; Pekrun et al., 2002; Spangler, Pekrun, Kramer, \& Hofmann, 2002) and four quantitative studies focusing on scale development (Pekrun, Goetz, Perry, Kramer, \& Hochstadt, 2004; Titz, 2001). The studies were guided by theory and were used to in form further development of theory based emotion taxonomies which, in turn, were employed to construct the final AEQ scales. Thus, the strategy used involved theory evidence loops integrating both rational and empirical perspectives (for more information, see Pekrun et al., 2004; Titz, 2001).

\subsubsection{Emotions assessed by the AEQ}

The decision to include scales for nine different emotions (enjoyment, hope, pride, relief, anger, anxiety, hopelessness, shame, and boredom) was based on two criteria. First, we selected emotions that occur frequently in students, as documented in our exploratory studies (Pekrun, 1992c; Pekrun et al., 2002; Titz, 2001). Second, we chose emotions to represent major emotion categories as defined by the three dimensional taxonomy outlined earlier. Accordingly, the AEQ addresses activity emotions (enjoy ment, boredom, and anger), prospective outcome emotions (hope, anxiety, and hopelessness), and retrospective outcome emotions (pride, relief, and shame). In terms of valence, the instrument measures both positive and negative emotions, and in terms of activation, it assesses both activating and deactivating emotions. As such, the AEQ makes up the four emotion categories compris ing the valence and activation dimensions: positive activating (enjoyment, hope, pride); positive deactivating (relief); negative activating (anger, anxiety, shame); and negative deactivating (hopelessness, boredom).

\subsubsection{Defining situational context and temporal specificity}

In line with the contextual specificity of achievement emo tions, we constructed separate scales for class related, learning 
related, and test related emotions. Regarding temporal specific ity, the original version of the AEQ is intended to measure stu dents' habitual, trait like achievement emotions. However, the instrument can be used to assess all three types of emotions mentioned earlier (trait, course specific, state) by adapting the instructions accordingly (see Pekrun, Goetz, Frenzel, \& Perry, 2011).

\subsubsection{Item and scale development}

Initial item development for the AEQ was based on student re ports obtained from our exploratory studies (Pekrun, 1992c; Titz 2001). Concerning test related anxiety, scale construction also in cluded items adapted from Sarason's (1984) Reactions to Tests Questionnaire and Hodapp and Benson's (1997) integrative test anxiety questionnaire. Conceptual considerations and the explor atory data were used to construct taxonomies for components of achievement emotions, and items assessing these components were formulated. The components considered in these taxonomies, and in the scales, pertain to affective, cognitive, motivational, and physiological facets for each of the emotions measured. An effort was made to construct items that ensure discriminant validity of scales measuring different emotions, including neighboring emo tions (i.e., like valenced emotions having similar antecedents and components; Kuppens, van Mechelen, Smits, \& de Boeck, 2004) that are difficult to separate empirically, such as anxiety and hopelessness.

The initial item pool consisted of more than 1500 items (Titz, 2001). From this pool, items were selected for preliminary ver sions of the scales by using expert judgment and criteria of semantic redundancy. Selection of items for the final scales was based on item and scale statistics for the preliminary versions (Pekrun et al., 2004; Titz, 2001). Again, in selecting items, we made an effort to attend to both convergent and divergent scale validity. Items were selected according to convergent item valid ity (i.e., high factor loadings on the relevant scale) as well as divergent item validity (i.e., low factor loadings on other emotion scales). The original German AEQ scales were translated into the English language by a team of three experts, two of them bilin gual. A backtranslation procedure was used to ensure content re lated item equivalence.

The final instrument consists of 24 scales that are organized in three sections assessing class related, learning related, and test related emotions (see Appendix for sample items and Pek run et al. (2011), for the complete instrument). Each of these scales contains items measuring the affective, cognitive, motiva tional, and physiological components of the respective emotion. A 5 point Likert scale $(1=$ completely disagree, $5=$ completely agree) is used to record item responses. The class related emo tion scales include 80 items and instruct students to report how they feel with regard to class related enjoyment, pride, an ger, anxiety, shame, hopelessness, and boredom. The learning re lated emotion scales include 75 items and instruct students to report how they feel with regard to studying in terms of the same eight emotions. Finally, the test emotion scales include 77 items and instruct students to indicate how they feel with re gard to test related enjoyment, hope, pride, relief, anger, anxiety, shame, and hopelessness. Within each section, the items are or dered in three blocks assessing emotional experiences before, during, and after an encounter with the specified academic con text. These blocks focus on activity emotions (during), prospec tive outcome emotions (before), and retrospective outcome emotions (after) related to the setting addressed. Sequencing items this way is in line with principles of situation reaction inventories and is intended to help respondents access their emotional memories (Endler \& Okada, 1975).

\subsection{Prior research using the $A E Q$}

Selected scales of the AEQ have successfully been used to assess relationships between achievement emotions and students' learn ing and academic performance. Scales of the AEQ served to exam ine the linkages between students' achievement goals and their class related and learning related emotions (Daniels et al., 2009; Mouratidis et al., 2009; Pekrun, Elliot, \& Maier, 2006, 2009). In line with the control value approach to goals and emotions proposed by Pekrun et al. (2006, 2009), mastery goals predicted activity emotions, and performance approach goals and performance avoidance goals predicted positive and negative outcome emo tions, respectively. Furthermore, these emotions were documented as mediators of the effects of achievement goals on students' aca demic performance (Daniels et al., 2009; Pekrun et al., 2009). In re search on test emotions (Pekrun et al., 2004), the test related emotion scales were also found to relate to students' learning and performance, with enjoyment, hope, and pride showing posi tive relations with most indicators of learning, and anger, anxiety, shame, and hopelessness showing negative relations. In addition, students' boredom has been analyzed using the learning related boredom scale of the AEQ (Acee et al., 2010; Pekrun et al., 2010). The findings suggest that boredom relates negatively to students' academic control, motivation to learn, use of flexible learning strat egies, self regulation of learning, and academic performance. Final ly, a domain specific variant of the instrument measuring students' emotions in mathematics (Achievement Emotions Questionnaire Mathematics, AEQ M) was employed to analyze differences in stu dents' mathematics emotions across genders, classrooms, and cul tures (e.g., Frenzel, Pekrun, \& Goetz, 2007; Frenzel, Thrash, Pekrun \& Goetz, 2007)

The findings of these studies suggest that the AEQ scales can be used to analyze various achievement emotions. However, since none of studies included more than a subset of scales, they did not provide a systematic account of the psychometric quality of the instrument and of the full range of emotions addressed by the AEQ. Therefore, we lack knowledge about the overall reliability and validity of the instrument. In particular, there is a research def icit regarding the internal component structures and interrelations of diverse achievement emotions as assessed by the AEQ and about the relationships of the full set of emotions with important antecedents and outcomes such as students' control value apprais als, learning, and academic performance.

\subsection{Aims of the present study}

Because a comprehensive analysis of the AEQ is lacking to date, the present research sought to analyze item and scale statistics, reliability, internal test validity, and external test validity for the complete instrument (see Slaney and Maraun (2008) for the dis tinction of internal versus external test validity). In doing so, we aimed to analyze the internal structures and external linkages of the various achievement emotions measured by the AEQ. Regard ing external linkages, the study examined the relationships be tween achievement emotions and their presumed antecedents and outcomes, as addressed by Pekrun's (2006) control value the ory of achievement emotions. We used a dataset involving a North American student sample previously employed by Pekrun et al (2004) to analyze select aspects of the AEQ test emotions scales, but made use of the entire dataset in analyzing all 24 scales of the instrument. The original version of the AEQ measuring stu dents' habitual achievement emotions experienced across aca demic achievement situations was used, implying that these emotions were measured as domain general, trait like variables. By assessing habitual, trait like achievement emotions, the present research analyzed emotions at the same level of generality as test 

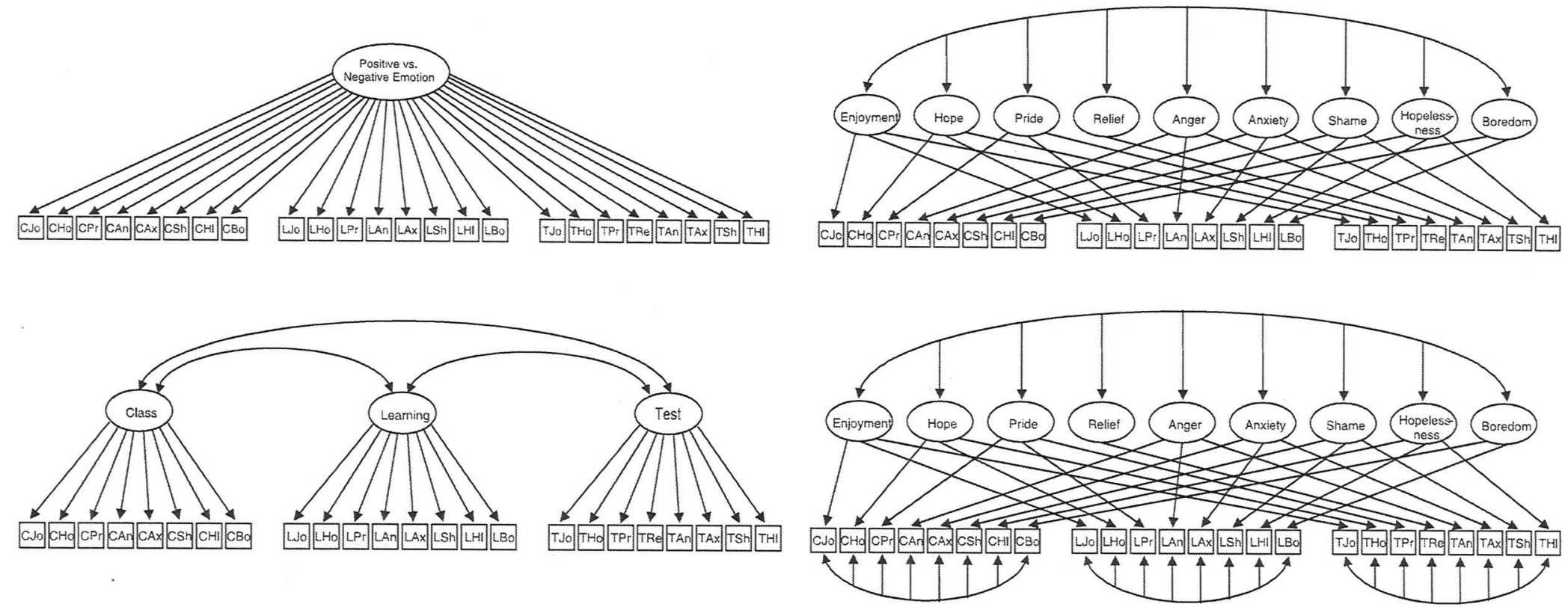

Fig. 2. SEM models for relationships between emotions. Upper left part: Model 2A (one emotion-factor model). Upper right part: Model 2B (eight emotion-factors model). Lower left part: Model 2C (three setting-factors model). Lower right part. Model $2 \mathrm{C}$ (emotion $\mathrm{x}$ setting-factors model). $\mathrm{C}, \mathrm{L}$, and $\mathrm{T}$ denote class-related, learning-related, and test-related emotions, respectively. Jo $=$ enjoyment, $\mathrm{Ho}=$ hope, $\mathrm{Pr}=\mathrm{pride}, \mathrm{Re}=$ relief, $\mathrm{An}=$ anger, $\mathrm{Ax}=$ anxiety. $\mathrm{HI}=$ hopelessness, $\mathrm{BO}=$ boredom. 
anxiety scales (Zeidner, 1998). Specifically, we focused on the fol lowing issues: (1) item and scale statistics, including reliabilities; (2) gender differences; (3) internal test validity of the scales with regard to the internal component structures of emotions; (4) inter nal test validity in terms of the relationships between emotions; and (5) external test validity in terms of relationships with stu dents' appraisals, learning, and performance.

With regard to gender, we sought to document the validity of the instrument in terms of replicating the gender differences in students' test anxiety that have consistently been found in prior re search (Hembree, 1988; Zeidner, 1998). With regard to the internal component structures of scales, we used confirmatory factor anal ysis (CFA) to examine if these structures are best captured by hier archical component factor models as described earlier, and compared these models to one factor models as well as component factor models involving independent components (Fig. 1).

Concerning the relations between emotions, correlational anal ysis and CFA were used to document the distinctness of the emo tion constructs assessed by the AEQ. We expected that a CFA model representing the two facet structure of the instrument (i.e., nine different emotions nested within three different achieve ment settings) would best fit the data, as compared with alterna tive models. The alternative models included a one factor mode representing positive versus negative emotions as one bipolar fac tor, as well as two models differentiating between emotions only, or between different settings only (Fig. 2).

With respect to relations with learning and achievement, we examined the linkages of emotions with all of the primary anteced ents and outcome variables addressed by the control value theory as described earlier, including control value appraisals (self effi cacy, academic control, academic value), intrinsic and extrinsic motivation, overall academic effort, use of flexible and rigid learn ing strategies (elaboration and rehearsal), self and external regu lation of learning, and academic performance.

\section{Method}

\subsection{Participants and procedure}

The sample consisted of 389 students (234 female; age: $M=20.63$ years; $S D=3.48$ ) in several undergraduate psychology courses at a large, Midwestern Canadian university who partici pated in return for extra course credit. Students were enrolled in study programs at different faculties including the faculties of arts (42.7\%), management (15.4\%), science $(12.6 \%)$, and nursing $(8.1 \%)$ The distribution of students across genders and faculties is typical for students participating in undergraduate psychology courses at Canadian universities (Perry, Stupnisky, Hall, Chipperfield, \& Wei ner, 2010). Participants completed the measures in one session.

\subsection{Measures}

\subsubsection{Achievement emotions}

To assess students' achievement emotions, the complete AEQ as described earlier was used (see Appendix for sample items). Stu dents were instructed to report how they felt, typically, when attending class, studying, or taking test and exams in their univer sity courses.

\subsubsection{Perceived control and value}

A 10 item version of Perry's (Perry et al., 2001) Perceived Aca demic Control Scale and the Self Efficacy for Learning and Perfor mance Scale of the Motivated Strategies for Learning Questionnaire (MSLQ; Pintrich, Smith, Garcia, \& McKeachie, 1991) were used to measure achievement related subjective con trol. The items of the Perceived Academic Control Scale relate to influencing academic performance (e.g., "I have a great deal of con trol over my academic performance in my courses": "The more ef fort I put in my courses, the better I do in them"). The Self Efficacy for Learning and Performance Scale consists of five items assessing students' confidence about being able to master academic tasks and get good grades (e.g., "I'm confident I can do an excellent job on the assignments and tests in courses at university"). Partici pants responded by using 1 (strongly disagree) to 5 (strongly agree) scales, and the scores were summed to form the two control in dexes $(\alpha=.83$ and .82 for academic control and self efficacy, respectively). Perceived academic value was assessed with a short four item version of the Task Value Scale of the MSLQ (Pintrich et al., 1991; e.g., "Understanding the subject matter of courses at university is very important to me"; "I am very interested in the content areas of courses at university"; $1=$ strongly disagree, 5 = strongly agree; $\alpha=.69$ ).

\subsubsection{Motivation}

The Intrinsic Goal Orientation, Extrinsic Goal Orientation, and Effort Regulation scales of the MSLQ (Pintrich et al., 1991) were in cluded in the study. The Intrinsic Goal Orientation and Extrinsic Goal Orientation scales are measures of intrinsic motivation based on interest and curiosity and of extrinsic motivation related to get ting good grades, respectively, with each scale comprised of four items (e.g., "In classes at university, I prefer course material that arouses my curiosity, even if it is difficult to learn"; "Getting good grades in classes at university is the most satisfying thing for me right now"). The Effort Regulation scale is a measure of students' overall effort and motivation to learn (four items; e.g.., "I work hard to do well in my classes even if I don't like what we are doing"). Participants responded by using 1 (strongly disagree) to 5 (strongly agree) scales, and the scores were summed to form the intrinsic motivation, extrinsic motivation, and effort indexes $(\alpha \mathrm{s}=.51$, .68, and .61 for intrinsic motivation, extrinsic motivation, and effort, respectively).

\subsubsection{Learning strategies}

As indicators of flexible versus rigid learning strategies, stu dents' use of elaboration and rehearsal strategies was assessed. Both strategies were measured with the respective scales of the MSLQ (Pintrich et al., 1991). The elaboration and rehearsal scales consisted of six and four items, respectively (e.g., "When reading for my classes, I try to relate the material to what I already know"; "When studying for my classes, I practice saying the material to myself over and over"). Participants responded by using 1 (strongly disagree) to 5 (strongly agree) scales, and the scores were summed to form the elaboration and rehearsal indexes $(\alpha \mathrm{s}=.73$ and .59 for elaboration and rehearsal, respectively).

\subsubsection{Self regulation versus external regulation of learning}

A four item version of Goetz' (2004) Perceived Self regulation of Learning Scale was used to measure students' self regulation of learning goals, use of strategies, and monitoring of learning out comes (e.g., "When studying, I set my own goals that I want to at tain"; "When studying difficult material, I decide for myself which strategy to use"; "I am able to evaluate for myself how I make pro gress at learning"). A four item version of Goetz' (2004) Perceived External Regulation of Learning Scale was used to measure exter nal regulation (e.g., "The way I study largely depends on the pro fessor's recommendations"; "When studying, I entirely rely on the readings I am given"). Participants responded by using 1 (strongly disagree) to 5 (strongly agree) scales, and the scores were summed to form the self regulation and external regulation in dexes $(\alpha \mathrm{s}=.72$ and .57 , respectively). 


\subsubsection{Academic performance}

Students' performance was measured by assessing their grade point average attained over the academic year prior to the study.

\section{Results and discussion}

\subsection{Item and scale statistics}

Table 1 shows response distributions, item total correlations, and reliabilities of the AEQ scales. The findings indicate that there was sufficient variation of scores on all scales. Most of the distribu tions were relatively symmetrical, the exception being the hope lessness scales which were positively skewed. Given the extreme nature and relatively rare occurrence of this emotion in achieve ment settings (Pekrun, 1992c; Titz, 2001), such skewness seems adequate and should not be reduced by normalizing distributions. Furthermore, the findings show that scale items had excellent part whole corrected item total correlations for all scales, with none of the correlations falling short of the .30 threshold. In line with item characteristics, reliabilities were above $\alpha=.75$ for all scales and above $\alpha=0.85$ for 15 of the 24 scales. In sum, these findings indi cate that the AEQ scales show sufficient variation, and that reliabil ities range from good to excellent.

\subsection{Gender differences}

In analyzing the scale statistics separately by gender, we found that means were significantly different for five emotions. As com pared with male students, female students reported more class re lated enjoyment $(M s=32.76$ and $30.95, S D s=6.49$ and 6.35 , for female and male students, respectively; $t[387]=2.68, p<.01$ ) and less class related anger $(M s=16.67$ and $18.34, S D s=6.00$ and $6.39 ; t[387]=-2.58, p<.05)$. Furthermore, female students re ported more learning related anxiety $(M s=31.57$ and 29.28, $S D s=7.90$ and $7.48 ; t[387]=2.82, p<.01)$, more test anxiety
$(M s=37.60$ and 34.08, SDs $=10.09$ and 9.53; $t[387]=3.39$, $p<.01)$, and less test related hope (Ms $=25.50$ and 26.59, $S D s=4.74$ and $5.15 ; t[387]=-2.12, p<.05)$. There were no signif icant mean differences for any of the other emotions.

In interpreting these gender differences, it should be noted that the effect sizes of the differences were relatively small (all $d s<.40$ ), and that none of the differences generalized across settings, with the single exception of anxiety which differed significantly for set tings of both learning and taking tests. The differences in self re ported anxiety are consistent with a vast literature showing that, on an average, female students report higher achievement anxiety than male students (Hembree, 1988; Zeidner, 1998). Given the consistency of this finding reported in the literature, the present findings attest to the convergent validity of the AEQ anxiety scales in terms of replicating these differences.

\subsection{Internal validity: component structures of emotions}

As noted, the AEQ scales were designed to represent the affec tive, cognitive, motivational, and physiological components of emotion within each scale. Following our earlier reasoning, we adopted the approach proposed by Hodapp and Benson (1997) to examine the validity of the scales in terms of their presumed inter nal structures. Three different structural models were competi tively tested for each scale (Fig. 1). Model 1A was a general factor model assuming one latent emotion factor, with all scale items being manifest indicators of this factor. Model $1 \mathrm{~B}$ was a four component factors model consisting of four separate latent factors representing the four emotion components, with the scale items being indicators for these factors. Model $1 \mathrm{C}$ was constructed as a hierarchical model that integrated the perspectives of the first two models by consisting of four latent primary component factors and one latent secondary emotion factor.

Given our component structuring of achievement emotions, we expected the component factors and hierarchical models to show

Table 1

Item and scale statistics.

\begin{tabular}{|c|c|c|c|c|c|c|c|c|}
\hline & No. of items & Possible range & Observed range & $M$ & $S D$ & Skewness & Mean $r_{i(t-i)^{d}}$ & Alpha \\
\hline \multicolumn{9}{|c|}{ Class-related emotions } \\
\hline Enjoyment & 10 & $10-50$ & $15-49$ & 31.99 & 6.47 & -.10 & .55 & .85 \\
\hline Hope & 8 & $8-40$ & $13-40$ & 27.39 & 4.67 & -.20 & .51 & .79 \\
\hline Pride & 9 & $9-45$ & $11-45$ & 31.20 & 5.50 & -.30 & .52 & .82 \\
\hline Anger & 9 & $9-45$ & $9-42$ & 17.39 & 6.24 & .75 & .58 & .86 \\
\hline Anxiety & 12 & $12-60$ & $12-56$ & 27.68 & 8.30 & .28 & .55 & .86 \\
\hline Shame & 11 & $11-55$ & $11-52$ & 25.22 & 8.80 & .38 & .63 & .89 \\
\hline Hopelessness & 10 & $10-50$ & $10-42$ & 17.56 & 6.68 & 1.04 & .67 & .90 \\
\hline Boredom & 11 & $11-55$ & $11-54$ & 30.84 & 9.88 & .06 & .74 & .93 \\
\hline \multicolumn{9}{|c|}{ Learning-related emotions } \\
\hline Enjoyment & 10 & $10-50$ & $14-49$ & 33.09 & 5.78 & -.24 & .44 & .78 \\
\hline Hope & 6 & $6-30$ & $10-30$ & 20.27 & 3.70 & -.11 & .52 & .77 \\
\hline Pride & 6 & $6-30$ & $9-30$ & 21.59 & 4.00 & -.38 & .45 & .75 \\
\hline Anger & 9 & $9-45$ & $9-42$ & 22.00 & 7.04 & .18 & .56 & .86 \\
\hline Anxiety & 11 & $11-55$ & $11-47$ & 30.69 & 7.76 & -.24 & .53 & .84 \\
\hline Shame & 11 & $11-55$ & $11-51$ & 27.00 & 8.32 & .29 & .57 & .86 \\
\hline Hopelessness & 11 & $11-55$ & $11-48$ & 23.06 & 8.09 & .58 & .62 & .90 \\
\hline Boredom & 11 & $11-55$ & $11-50$ & 30.69 & 9.29 & -.09 & .70 & .92 \\
\hline \multicolumn{9}{|l|}{ Test Emotions } \\
\hline Enjoyment & 10 & $10-50$ & $10-46$ & 28.33 & 6.00 & .01 & .45 & .78 \\
\hline Hope & 8 & $8-40$ & $13-39$ & 25.91 & 4.93 & .09 & .52 & .80 \\
\hline Pride & 10 & $10-50$ & $14-48$ & 31.32 & 6.48 & -.16 & .58 & .86 \\
\hline Relief & 6 & $6-30$ & $6-30$ & 21.51 & 4.26 & -.39 & .52 & .77 \\
\hline Anger & 10 & $10-50$ & $10-43$ & 23.36 & 7.28 & .26 & .57 & .86 \\
\hline Anxiety & 12 & $12-60$ & $14-60$ & 36.19 & 9.97 & -.01 & .62 & .90 \\
\hline Shame & 10 & $10-50$ & $10-44$ & 21.92 & 7.52 & .43 & .60 & .87 \\
\hline Hopelessness & 11 & $11-55$ & $11-47$ & 22.12 & 8.42 & .65 & .69 & .92 \\
\hline
\end{tabular}

\footnotetext{
a Median of part-whole corrected item-total correlations.
} 
Table 2

Emotion component structures of AEQ scales: confirmatory factor analysis.

\begin{tabular}{|c|c|c|c|c|c|c|c|c|c|c|c|c|c|c|c|c|}
\hline \multirow[b]{2}{*}{ Emotion } & \multirow[b]{2}{*}{ Model } & \multicolumn{5}{|c|}{ Class-related emotions } & \multicolumn{5}{|c|}{ Learning-related emotions } & \multicolumn{5}{|c|}{ Test emotions } \\
\hline & & $\chi^{2}$ & $d f$ & GFI & CFI & RMSEA & $\chi^{2}$ & $d f$ & GFI & CFI & RMSEA & $\chi^{2}$ & $d f$ & GFI & CFI & RMSEA \\
\hline \multirow[t]{3}{*}{ Enjoyment } & 1 & 117 & 32 & .94 & .97 & .083 & 164 & 33 & .92 & .91 & .102 & 119 & 34 & .94 & .89 & .081 \\
\hline & 2 & 80 & 27 & .96 & .98 & .072 & 83 & 27 & .96 & .96 & .073 & 64 & 28 & .97 & .95 & .058 \\
\hline & 3 & 89 & 29 & .96 & .98 & .073 & 85 & 29 & .96 & .96 & .071 & 71 & 30 & .96 & .94 & .060 \\
\hline \multirow[t]{3}{*}{ Hope } & 1 & 43 & 20 & .97 & .98 & .045 & 46 & 9 & .96 & .95 & .103 & 75 & 20 & .95 & .94 & .085 \\
\hline & 2 & 32 & 17 & .98 & .99 & .048 & 18 & 6 & .98 & .98 & .073 & 43 & 17 & .97 & .97 & .063 \\
\hline & 3 & 32 & 17 & .98 & .99 & .048 & 18 & 6 & .98 & .98 & .073 & 43 & 17 & .97 & .97 & .063 \\
\hline \multirow[t]{3}{*}{ Pride } & 1 & 61 & 27 & .97 & .98 & .057 & 93 & 8 & .93 & .88 & .166 & 113 & 32 & .94 & .94 & .082 \\
\hline & 2 & 45 & 23 & .97 & .99 & .049 & 5 & 4 & 1.00 & 1.00 & .022 & 64 & 26 & .97 & .97 & .062 \\
\hline & 3 & 60 & 25 & .97 & .98 & .061 & 18 & 6 & .98 & .98 & .074 & 86 & 28 & .96 & .96 & .074 \\
\hline \multirow[t]{3}{*}{ Relief } & 1 & & & & & & & & & & & 39 & 13 & .97 & .96 & .072 \\
\hline & 2 & & & & & & & & & & & 26 & 12 & .98 & .98 & .056 \\
\hline & 3 & & & & & & & & & & & 26 & 12 & .98 & .98 & .056 \\
\hline \multirow[t]{3}{*}{ Anger } & 1 & 128 & 27 & .93 & .97 & .099 & 196 & 27 & .90 & .94 & .127 & 97 & 33 & .95 & .95 & .071 \\
\hline & 2 & 43 & 21 & .98 & .99 & .053 & 57 & 18 & .97 & .99 & .075 & 45 & 27 & .98 & .98 & .042 \\
\hline & 3 & 46 & 23 & .97 & .99 & .052 & 72 & 20 & .96 & .98 & .082 & 52 & 29 & .97 & .98 & .046 \\
\hline \multirow[t]{3}{*}{ Anxiety } & 1 & 475 & 51 & .83 & .91 & .147 & 172 & 44 & .93 & .95 & .087 & 228 & 53 & .91 & .92 & .093 \\
\hline & 2 & 138 & 45 & .94 & .97 & .073 & 133 & 38 & .94 & .96 & .080 & 95 & 47 & .96 & .98 & .052 \\
\hline & 3 & 144 & 47 & .94 & .97 & .073 & 134 & 40 & .94 & .96 & .078 & 110 & 49 & .95 & .97 & .057 \\
\hline \multirow[t]{3}{*}{ Shame } & 1 & 363 & 38 & .94 & .98 & .080 & 123 & 44 & .95 & .97 & .068 & 107 & 33 & .95 & .95 & .076 \\
\hline & 2 & 301 & 32 & .95 & .98 & .079 & 98 & 39 & .96 & .98 & .063 & 100 & 27 & .95 & .95 & .084 \\
\hline & 3 & 304 & 34 & .95 & .98 & .078 & 105 & 41 & .95 & .98 & .064 & 104 & 29 & .95 & .95 & .082 \\
\hline \multirow[t]{3}{*}{ Hopelessness } & 1 & 97 & 34 & .95 & .98 & .069 & 92 & 44 & .96 & .99 & .053 & 92 & 44 & .96 & .98 & .054 \\
\hline & 2 & 80 & 28 & .95 & .98 & .069 & 56 & 38 & .97 & 1.00 & .035 & 82 & 38 & .96 & .98 & .055 \\
\hline & 3 & 89 & 30 & .96 & .99 & .071 & 56 & 40 & .97 & 1.00 & .033 & 83 & 40 & .96 & .98 & .053 \\
\hline \multirow[t]{3}{*}{ Boredom } & 1 & 141 & 44 & .94 & .99 & .075 & 238 & 44 & .90 & .97 & .107 & & & & & \\
\hline & 2 & 114 & 38 & .95 & .99 & .072 & 127 & 37 & .94 & .98 & .080 & & & & & \\
\hline & 3 & 127 & 40 & .94 & .99 & .075 & 130 & 39 & .94 & .98 & .078 & & & & & \\
\hline
\end{tabular}

superior fit, as compared with the one factor models. We expected the fit of the hierarchical models to be similar to the fit of the com ponent factors models, indicating that combining the four factors under the umbrella of one second order emotion factor is sup ported empirically. Although the hierarchical models represented our theoretical conception, we did not expect them to show better fit than the component factors models, since they involved estima tion of one more latent factor.

Structural equation modeling (LISREL 8.80; Jöreskog \& Sörbom, 2006) was used to test the fit of the three models for each of the 24 scales (Table 2). Following Hoyle and Panter's (1995) recommen dations, we used both absolute and incremental fit indexes to eval uate the models, including the $\chi^{2} / d f$ ratio, the goodness of fit index $(G F I)$, the comparative fit Index $(C F I)$, and the root mean square error of approximation (RMSEA). CFIs above .95 and RMSEAs below .05 are thought to indicate good fit, RMSEAs between .05 and .08 reasonable fit, and RMSEAs between .08 and .10 mediocre fit. We adopted Cheung and Rensvold's (2002) cut off criteria for eval uating differences of fit between models, with a loss of fit of $\Delta C F I>.01$ being regarded as substantial.

Using these criteria, model fit of the component factors and hierarchical models was at least reasonable for all of the scales and good for the vast majority of the scales (Table 2). In contrast, the one factor models showed a poor fit for $\mathbf{1 0}$ of the scales in terms of CFI being below .95, and for 14 scales in terms of RMSEA being above .08 . Furthermore, a direct comparison shows that the fit for the component factors and hierarchical models was clearly superior for most of the scales, as compared with the fit for the one factor models.

These findings indicate that scale construction was successful in terms of internal, structural validity. As such, the findings show that test anxiety is not the only emotion for which internal compo nent structures should be taken into account. For most of the scales, the component factors and hierarchical models which dif ferentiated between emotion components fit better than one fac tor models, thus corroborating our propositions on the internal structures of achievement emotions.

\subsection{Internal validity: relationships between emotions}

\subsubsection{Correlational analysis}

Our theoretical conception posits that it is useful to distin guish (a) between the different discrete emotions that occur within a given achievement setting (class related, learning re lated, test related), and (b) between the emotions experienced in different achievement settings. Pearson product moment cor relations were computed to test these propositions. As may be seen from Table 3 , the positive emotions enjoyment, hope, and pride correlated positively in all three settings. Similarly, there were positive correlations between the negative emotions anger, anxiety, shame, hopelessness, and boredom. The correlations be tween these positive emotions, on the one hand, and negative emotions, on the other hand, were moderately negative. However, diverging from the pattern of positive relationships between like valenced emotions, test related relief correlated positively with test related pride and anxiety, thus showing connections to one positive and one negative emotion. The relationship with anxiety is likely due to relief occurring when anxiety inducing threat is reduced, suggesting that relief is often preceded by anxiety, and that students who habitually experience relief during or after test situations also habitually experience anxiety in these same situations.

Overall, these findings show that the emotion constructs mea sured by the AEQ are clearly separable. This also is true for emo tions that might be presumed to constitute opposite ends of a bipolar continuum, such as enjoyment and boredom, or hope and 
Table 3

Manifest intercorrelations of AEQ scales.

\begin{tabular}{|c|c|c|c|c|c|c|c|c|c|}
\hline & 1 & 2 & 3 & 4 & 5 & 6 & 7 & 8 & 9 \\
\hline \multicolumn{10}{|c|}{ Correlations within settings } \\
\hline \multicolumn{10}{|l|}{1 Enjoyment } \\
\hline 2 Hope & $\begin{array}{l}.71 \\
.64 \\
.70\end{array}$ & & & & & & & & \\
\hline 3 Pride & $\begin{array}{l}.62 \\
.72 \\
.71\end{array}$ & $\begin{array}{l}.68 \\
.64 \\
.68\end{array}$ & & & & & & & \\
\hline 4 Relief & .06 & -.04 & .22 & & & & & & \\
\hline 5 Anger & $\begin{array}{l}-.40 \\
-.44 \\
-.24\end{array}$ & $\begin{array}{l}-.35 \\
-.52 \\
-.36\end{array}$ & $\begin{array}{l}-.21 \\
-.33 \\
-.20\end{array}$ & $\begin{array}{l}- \\
- \\
.08\end{array}$ & & & & & \\
\hline 6 Anxiety & $\begin{array}{l}-.24 \\
-.12 \\
-.38\end{array}$ & $\begin{array}{l}-.36 \\
-.42 \\
-.48\end{array}$ & $\begin{array}{l}-.15 \\
-.15 \\
-.29\end{array}$ & $\begin{array}{l}- \\
- \\
.36\end{array}$ & $\begin{array}{l}.64 \\
.61 \\
.57\end{array}$ & & & & \\
\hline 7 Shame & $\begin{array}{l}-.26 \\
-.15 \\
-.29\end{array}$ & $\begin{array}{l}-.34 \\
-.43 \\
-.42\end{array}$ & $\begin{array}{l}-.19 \\
-.23 \\
-.37\end{array}$ & $\begin{array}{l}- \\
- \\
.06\end{array}$ & $\begin{array}{l}.58 \\
.56 \\
.63\end{array}$ & $\begin{array}{l}.79 \\
.68 \\
.65\end{array}$ & & & \\
\hline 8 Hopelessness & $\begin{array}{l}-.34 \\
-.33 \\
-.38\end{array}$ & $\begin{array}{l}-.44 \\
-.58 \\
-.52\end{array}$ & $\begin{array}{l}-.26 \\
-.43 \\
-.40\end{array}$ & $\begin{array}{l}- \\
- \\
.00\end{array}$ & $\begin{array}{l}.76 \\
.67 \\
.72\end{array}$ & $\begin{array}{l}.69 \\
.68 \\
.67\end{array}$ & $\begin{array}{l}.62 \\
.75 \\
.78\end{array}$ & & \\
\hline 9 Boredom & $\begin{array}{l}-.57 \\
-.51\end{array}$ & $\begin{array}{l}-.42 \\
-.48\end{array}$ & $\begin{array}{l}-.27 \\
-.38\end{array}$ & - & $\begin{array}{l}.62 \\
.76\end{array}$ & $\begin{array}{l}.46 \\
.49\end{array}$ & $\begin{array}{l}.40 \\
.50\end{array}$ & $\begin{array}{l}.50 \\
.58\end{array}$ & \\
\hline \multicolumn{10}{|c|}{ Correlations across settings } \\
\hline Class versus learning & .61 & .52 & .59 & - & .61 & .66 & .71 & .73 & .73 \\
\hline Class versus test & .47 & .57 & .60 & - & .74 & .63 & .71 & .77 & - \\
\hline Learning versus test & .58 & .62 & .60 & - & .69 & .74 & .78 & .81 & - \\
\hline
\end{tabular}

Note: Within each block, upper/middle/lower coefficients are for class-, learningand test-related emotions, respectively. For relief, test-related relief was assessed only. For boredom, class-related and learning-related boredom were assessed only. $p<.05 / .01$ for $|r|>.10 / .14$.

hopelessness, which showed no more than moderately negative relationships. Indeed, the strongest relationships were found for neighboring, like valenced emotions such as enjoyment and hope, or anxiety, shame, and hopelessness. In interpreting these correla tions, it is important to note that the present study used the AEQ to assess students' habitual, trait like emotions. Neighboring trait emotions are known to be strongly correlated (for a conceptual dis cussion, see Pekrun et al., 2004; also see Watson \& Clark, 1992), in contrast to state emotions that show more divergence (e.g., Goetz, 2004; Goetz, Preckel, Pekrun, \& Hall, 2007).

Furthermore, as expected, the correlations also indicate that the emotions were separable across the three settings examined ( $\mathrm{Ta}$ ble 3). Correlations were moderate for the positive emotions, and stronger for some of the negative emotions. The strongest correla tions across class, studying, and taking tests were found for stu dents' hopelessness and shame. These emotions showed substantial generalization across situations, thus representing gen eralized individual dispositions in the achievement domain in the present student sample.

\subsubsection{Structural equation modeling of latent relationships}

In order to more fully assess the relationships between achievement emotions, structural equation modeling was em ployed (LISREL 8.80, Jöreskog \& Sörbom, 2006). As noted, we con structed four models and tested them competitively, aiming to document the distinctness of the emotion constructs assessed by the AEQ. The 24 scales of the instrument served as manifest indicators in each model (Fig. 2). Model 2A was a one factor model assuming that the interrelations between achievement emo tions can be explained by one general bipolar factor, with positive emotions having positive factor loadings and negative emotions negative loadings on this single factor. Model 2B consisted of nine latent factors made up of the nine discrete emotions assessed by the AEQ (enjoyment, hope, pride, relief, anger, anxiety, shame, hopelessness, and boredom). Indicators for the factors were the emotion scales pertaining to the respective emotion. For example, the class related, learning related, and test related enjoyment scales served as indicators for the enjoyment factor. For relief, there was one manifest indicator only (the test relief scale). The factor loading for this indicator was fixed to the reliability of the scale (.77).

Model 2C was a three settings model comprised of three latent factors representing emotions experienced in the three settings ad dressed by the AEQ. The class related, learning related, and test related emotion scales served as indicators for the class related, learning related, and test emotions factors, respectively. Model 2D sought to fully represent the two facet structure of the AEQ by simultaneously taking the nine discrete emotions and the three settings into account. Following recommendations by Marsh, By rne, and Craven (1993), a correlated uniquenesses approach was used to construct this model. The nine discrete emotions were rep resented by nine latent factors, and the influences of the three set tings were taken into account by letting the uniquenesses of scales correlate within settings.

To test model fit, we used the same set of indicators as de scribed earlier. The one factor model had a poor fit to the data, with $\chi^{2}(252)=5647.78, G F I=.42, C F I=.81$, and $R M S E A=.250$. The fit for the nine emotions factor model was substantially better, although not satisfactory either, with $\chi^{2}(217)=2349.25, G F I=.64$, $C F I=.92$, and $R M S E A=.170$. Similarly, the three settings factor model had a poor fit, with $\chi^{2}(249)=5866.39, G F I=.41, C F I=.83$, and $R M S E A=.257$. In marked contrast, the two facet, emo tion $\times$ setting model showed a reasonable fit, with $\chi^{2}$ $(134)=370.78, G F I=.92, C F I=.99$, and $R M S E A=.072$. In line with our theoretical perspective, these findings demonstrate that the relationships between different achievement emotions can be best explained by taking into account both the differences between dis crete emotions and the differences between emotions that occur in different achievement settings.

Furthermore, the two facet model provides estimates of the la tent relationships between the nine emotions (Table 4). In line with the manifest correlations, these relationships were positive for enjoyment, hope, and pride; positive for anger, anxiety, shame, hopelessness, and boredom; and negative between these positive and negative emotions. Again, relief was an exception from this pattern. Relief correlated positively with two positive emotions (enjoyment and pride) and three negative emotions (anxiety, shame, and boredom). Importantly, although some of the relation ships between neighboring emotions, such as enjoyment and hope,

Table 4

Two-facet model: latent correlations between emotions.

\begin{tabular}{|c|c|c|c|c|c|c|c|c|}
\hline & 1 & 2 & 3 & 4 & 5 & 6 & 7 & 8 \\
\hline \multicolumn{9}{|l|}{1 Enjoyment } \\
\hline 2 Hope & $.82^{\circ *}$ & & & & & & & \\
\hline 3 Pride & $.78^{*+}$ & $.82^{* *}$ & & & & & & \\
\hline 4 Relief & $.21^{* *}$ & $.11^{\star}$ & $.30^{\circ}$ & & & & & \\
\hline 5 Anger & $-.43^{\kappa *}$ & $-.49^{\circ *}$ & $-.28^{* *}$ & .08 & & & & \\
\hline 6 Anxiety & $-.22^{\circ " \prime}$ & $-.48^{* 0}$ & $-.20^{* *}$ & $.30^{*+}$ & $.79^{-*}$ & & & \\
\hline 7 Shame & $-.22^{\times *}$ & $-.47^{\circ}$ & $-.26^{* *}$ & $.24^{*}$ & .72 & $.90^{*}$ & & \\
\hline 8 Hopelessness & $-.38^{* x}$ & $-.62^{\circ}$ & $-.42^{\circ}$ & .04 & $.86^{\circ}$ & $.84^{\circ 4}$ & $.86^{*}$ & \\
\hline 9 Boredom & $-.60^{\mu \omega}$ & $-.51^{* *}$ & $-.36^{* *}$ & $.16^{*}$ & $.76^{* *}$ & $.58^{\star \circ}$ & $.53^{\circ}$ & $.66^{2 *}$ \\
\hline
\end{tabular}


Table 5

Correlations of achievement emotions with appraisals, learning, and performance.

\begin{tabular}{|c|c|c|c|c|c|c|c|c|c|c|c|}
\hline \multirow[b]{2}{*}{ Emotion } & \multicolumn{3}{|l|}{ Appraisals } & \multicolumn{3}{|c|}{ Motivation } & \multicolumn{4}{|l|}{ Strategies } & \multirow{2}{*}{$\begin{array}{l}\text { Performance } \\
\text { GPA at } \\
\text { University }\end{array}$} \\
\hline & $\begin{array}{l}\text { Academic } \\
\text { control }\end{array}$ & $\begin{array}{l}\text { Self- } \\
\text { efficacy }\end{array}$ & $\begin{array}{l}\text { Task } \\
\text { value }\end{array}$ & Intrinsic & Extrinsic & Effort & Elaboration & Rehearsal & $\begin{array}{l}\text { Self- } \\
\text { regulation }\end{array}$ & $\begin{array}{l}\text { External } \\
\text { regulation }\end{array}$ & \\
\hline Enjoyment & $\begin{array}{l}.32 \\
.32 \\
.20\end{array}$ & $\begin{array}{l}.37 \\
.44 \\
.50\end{array}$ & $\begin{array}{l}.55 \\
.51 \\
.35\end{array}$ & $\begin{array}{l}.45 \\
.49 \\
.37\end{array}$ & $\begin{array}{l}.14 \\
.22 \\
.12\end{array}$ & $\begin{array}{l}.29 \\
.37 \\
.37\end{array}$ & $\begin{array}{l}.40 \\
.42 \\
.38\end{array}$ & $\begin{array}{l}.21 \\
.19 \\
.23\end{array}$ & $\begin{array}{l}.26 \\
.34 \\
.38\end{array}$ & $\begin{array}{l}-.07 \\
-.01 \\
-.02\end{array}$ & $\begin{array}{l}.15 \\
.22 \\
.26\end{array}$ \\
\hline Hope & $\begin{array}{l}.40 \\
.43 \\
.35\end{array}$ & $\begin{array}{l}.53 \\
.56 \\
.60\end{array}$ & $\begin{array}{l}.47 \\
.41 \\
.37\end{array}$ & $\begin{array}{l}.41 \\
.43 \\
.40\end{array}$ & $\begin{array}{l}.16 \\
.07 \\
.04\end{array}$ & $\begin{array}{l}.38 \\
.47 \\
.44\end{array}$ & $\begin{array}{l}.44 \\
.40 \\
.40\end{array}$ & $\begin{array}{l}.25 \\
.09 \\
.18\end{array}$ & $\begin{array}{l}.45 \\
.51 \\
.51\end{array}$ & $\begin{array}{l}-.03 \\
-.14 \\
-.05\end{array}$ & $\begin{array}{l}.19 \\
.33 \\
.25\end{array}$ \\
\hline Pride & $\begin{array}{l}.37 \\
.44 \\
.33\end{array}$ & $\begin{array}{l}.51 \\
.49 \\
.56\end{array}$ & $\begin{array}{l}.44 \\
.44 \\
.32\end{array}$ & $\begin{array}{l}.35 \\
.40 \\
.34\end{array}$ & $\begin{array}{l}.34 \\
.26 \\
.17\end{array}$ & $\begin{array}{l}.36 \\
.42 \\
.42\end{array}$ & $\begin{array}{l}.42 \\
.42 \\
.44\end{array}$ & $\begin{array}{l}.32 \\
.28 \\
.31\end{array}$ & $\begin{array}{l}.43 \\
.46 \\
.49\end{array}$ & $\begin{array}{l}.12 \\
.03 \\
.06\end{array}$ & $\begin{array}{l}.15 \\
.29 \\
.34\end{array}$ \\
\hline Relief & .17 & .07 & .15 & .05 & .25 & .04 & .21 & .20 & .14 & .23 & .14 \\
\hline Anger & $\begin{array}{l}-.60 \\
-.41 \\
-.54\end{array}$ & $\begin{array}{l}-.35 \\
-.39 \\
-.40\end{array}$ & $\begin{array}{l}-.44 \\
-.33 \\
-.32\end{array}$ & $\begin{array}{l}-.22 \\
-.27 \\
-.20\end{array}$ & $\begin{array}{r}-.05 \\
.02 \\
.08\end{array}$ & $\begin{array}{l}-.38 \\
-.43 \\
-.37\end{array}$ & $\begin{array}{l}-.30 \\
-.29 \\
-.29\end{array}$ & $\begin{array}{l}-.11 \\
-.02 \\
-.03\end{array}$ & $\begin{array}{l}-.25 \\
-.31 \\
-.30\end{array}$ & $\begin{array}{l}.28 \\
.29 \\
.34\end{array}$ & $\begin{array}{l}-.27 \\
-.25 \\
-.32\end{array}$ \\
\hline Anxiety & $\begin{array}{l}-.47 \\
-.30 \\
-.30\end{array}$ & $\begin{array}{l}-.39 \\
-.35 \\
-.38\end{array}$ & $\begin{array}{l}-.18 \\
-.08 \\
-.13\end{array}$ & $\begin{array}{l}-.10 \\
-.11 \\
-.16\end{array}$ & $\begin{array}{l}.16 \\
.20 \\
.27\end{array}$ & $\begin{array}{l}-.33 \\
-.30 \\
-.28\end{array}$ & $\begin{array}{l}-.18 \\
-.13 \\
-.11\end{array}$ & $\begin{array}{l}.02 \\
.08 \\
.12\end{array}$ & $\begin{array}{l}-.29 \\
-.30 \\
-.28\end{array}$ & $\begin{array}{l}.32 \\
.35 \\
.33\end{array}$ & $\begin{array}{l}-.18 \\
-.14 \\
-.14\end{array}$ \\
\hline Shame & $\begin{array}{l}-.48 \\
-.41 \\
-.47\end{array}$ & $\begin{array}{l}-.34 \\
-.35 \\
-.43\end{array}$ & $\begin{array}{l}-.21 \\
-.15 \\
-.19\end{array}$ & $\begin{array}{l}-.10 \\
-.08 \\
-.08\end{array}$ & $\begin{array}{l}.14 \\
.17 \\
.18\end{array}$ & $\begin{array}{l}-.31 \\
-.41 \\
-.38\end{array}$ & $\begin{array}{l}-.18 \\
-.19 \\
-.25\end{array}$ & $\begin{array}{r}.02 \\
.03 \\
-.01\end{array}$ & $\begin{array}{l}-.26 \\
-.35 \\
-.37\end{array}$ & $\begin{array}{l}.23 \\
.30 \\
.23\end{array}$ & $\begin{array}{l}-.18 \\
-.27 \\
-.37\end{array}$ \\
\hline Hopelessness & $\begin{array}{l}-.67 \\
-.62 \\
-.60\end{array}$ & $\begin{array}{l}-.45 \\
-.51 \\
-.51\end{array}$ & $\begin{array}{l}-.40 \\
-.29 \\
-.33\end{array}$ & $\begin{array}{l}-.26 \\
-.26 \\
-.23\end{array}$ & $\begin{array}{r}-.02 \\
.11 \\
.09\end{array}$ & $\begin{array}{l}-.41 \\
-.45 \\
-.45\end{array}$ & $\begin{array}{l}-.39 \\
-.36 \\
-.35\end{array}$ & $\begin{array}{l}-.11 \\
-.03 \\
-.04\end{array}$ & $\begin{array}{l}-.34 \\
-.46 \\
-.41\end{array}$ & $\begin{array}{l}.23 \\
.33 \\
.25\end{array}$ & $\begin{array}{l}-.31 \\
-.32 \\
-.34\end{array}$ \\
\hline Boredom & $\begin{array}{l}-.29 \\
-.32\end{array}$ & $\begin{array}{l}-.27 \\
-.34\end{array}$ & $\begin{array}{l}-.38 \\
-.38\end{array}$ & $\begin{array}{l}-.23 \\
-.26\end{array}$ & $\begin{array}{r}.00 \\
-.02\end{array}$ & $\begin{array}{l}-.42 \\
-.48\end{array}$ & $\begin{array}{l}-.19 \\
-.26\end{array}$ & $\begin{array}{l}-.04 \\
-.05\end{array}$ & $\begin{array}{l}-.16 \\
-.28\end{array}$ & $\begin{array}{l}.25 \\
.24\end{array}$ & $\begin{array}{l}-.15 \\
-.24\end{array}$ \\
\hline
\end{tabular}

Note: Within each block, upper/middle/lower coefficients are for class-, learning-, and test-related emotions, respectively. For relief, test-related relief was assessed only. For boredom, class-related and learning-related boredom were assessed only.

$p<.05 / .01$ for $|r|>.10 / .14$.

were high, they clearly indicate that all of the emotion constructs are separable, given that the latent coefficients were corrected for unreliability and represent the hightest possible estimates for these relationships.

3.5. External validity: linkages with students' appraisals, learning, and performance

\subsubsection{Relationships with control and value appraisals}

Table 5 shows the correlations of students' control value appraisals and the AEQ achievement emotions. As predicted by Pekrun's (2006) control value theory described earlier, there were clear linkages between appraisals and emotions. Academic control, self efficacy, and task value correlated generally positively with the positive emotions and negatively with the negative emotions. Regarding value, it should be noted that this variable was opera tionalized as positive task value in the present study. The con trol value theory proposes that the negative value of failure contributes to students' negative outcome emotions such as anxi ety, shame, and hopelessness, but this proposition was not tested in the present study.

\subsubsection{Relationships with learning and performance}

As expected, there also were clear linkages between the emo tions and variables of learning and performance, with different patterns of relations for different groups of emotions (Table 5). Specifically, the positive activating emotions enjoyment, hope and pride related positively to intrinsic motivation, effort, elabo ration of learning material, and self regulation of learning. In contrast, most of the correlations with external regulation were zero for these emotions. In line with the positive relationships with variables of learning, the correlations with students' GPA were positive as well. Relationships with GPA were stronger for learning related and test related positive activating emotions, as compared with the class related emotions within this category.

The negative deactivating emotions hopelessness and boredom showed the opposite pattern of linkages in terms of uniformly neg ative correlations with intrinsic motivation, effort, elaboration, self regulation, and academic performance. Furthermore, these emotions correlated positively with students' perceived external regulation of learning. Overall, the pattern of relationships corrob orates that positive activating emotions are likely beneficial for students' engagement and learning, whereas negative deactivating emotions are likely detrimental, as posited by the control value theory.

As expected, relationships were more complex for the negative activating emotions anger, anxiety, and shame. On the one hand, all three emotions correlated negatively with intrinsic motivation, elaboration, and self regulation. On the other hand, anxiety and shame correlated positively with students' extrinsic motivation targeting achievement outcomes, and test anxiety correlated posi tively with rehearsal of learning material. These findings are in line with the control value theory's proposition that negative activat ing emotions can exert variable effects on students' learning. De spite these variable effects, however, anger, anxiety, and shame related negatively to students' overall self reported effort at learn ing and to their academic performance.

These findings demonstrate the external validity of the AEQ scales and show that students' emotions have substantial linkages with their engagement and performance. Many of these relation ships proved to be rather strong, with correlations in the .30 .50 range. Interestingly, these relationships were relatively weak for test anxiety, as compared with other achievement emotions. For 
example, whereas the correlation between the AEQ test hopeless ness scale and students' GPA was $r=-.34$, the correlation for test anxiety was $r=-.14$ in the present research a low correlation which is quite typical for the range of correlations produced by test anxiety studies (Hembree, 1988). The findings of the present study thus reinforce the premise that research on students' affect is well advised to move on from test anxiety to include a broader range of emotions experienced in academic settings.

\section{Conclusions}

From a measurement perspective, the findings of the present research corroborate the reliability and validity of the AEQ. From the perspective of substantive research, they underscore the importance of distinguishing between discrete achievement emo tions and show that these emotions relate meaningfully to stu dents' learning and performance. Specifically, the findings indicate that the item statistics and reliabilities of the AEQ scales are good to excellent, and that the scales are well suited to de scribe the internal structures of achievement emotions in terms of their affective, cognitive, motivational, and physiological com ponents. Furthermore, the results of structural equation modeling confirmed that students' emotional experiences, and the AEQ scales assessing these experiences, can be organized by distin guishing between various discrete emotions, and between differ ent academic settings in which these emotions are experienced. Generally, these results suggest that measures of students' achievement emotions should consider the component structures of these emotions, the differences between discrete emotions, and the differences between emotional experiences across different academic settings.

Finally, the findings show that students' achievement emotions are linked to their control and value appraisals, motivation, use of learning strategies, self regulation of learning, and academic per formance. In so doing, they corroborate the external validity of the scales as well as propositions of Pekrun's (2006) control value theory. Whereas the positive activating emotions enjoyment, hope, and pride related positively to most of the variables measured, these relationships were negative for the deactivating emotions hopelessness and boredom. As expected, the pattern of linkages was more complex for the activating negative emotions anger, anx iety, and shame; however, the relationships with students' overall self reported effort, and with their academic performance, were negative as well.

Although these findings substantiate the psychometric quality of the AEQ and our study hypotheses, there also are clear limita tions in the present research. First, the sample consisted of North American undergraduate students only. While studies with Ger man and Chinese student samples using variants of the AEQ have produced similar findings and attest to the cross cultural useability of the instrument (Frenzel, Thrash, et al., 2007; Pekrun et al., 2010; Titz, 2001), it is open to question whether the findings generalize cross culturally to other populations as well. Similarly, while first attempts to use variants of the instrument with younger students proved successful (Frenzel, Pekrun, et al., 2007; Frenzel, Thrash, et al., 2007; Lichtenfeld, Pekrun, Stupnisky, Reiss, \& Murayama, 2010), more research is needed testing the psychometric quality of the instrument with $\mathrm{K} 12$ students and older adult populations. To make appropriate use of the scales with these populations, cog nitive validation of the content validity of items would be useful (Karabenick et al., 2007).

Second, the present research used the original version of the AEQ that assesses students' achievement emotions as domain general, trait like constructs, similar to the construct of test anxiety. Recent research has shown that students' emotions are partially organized in domain specific ways (Goetz, Frenzel, Pek run, Hall, \& Lüdtke, 2007). Research using domain specific vari ants of the AEQ, such as the Achievement Emotions Questionnaire Mathematics (AEQ M), corroborates the psycho metric quality of these variants. However, instruments such as the AEQ $M$ do not assess the full range of emotions and settings addressed by the original AEQ. Using the full instrument for assessing domain specific achievement emotions, and analyzing the generalizability of the current study findings to domain spe cific emotions, remains a task for future research. Similarly, fu ture research should more fully examine the utility of the AEQ for measuring state achievement emotions. Similar to trait mea sures of emotions more generally, some of the intercorrelations between emotions were relatively high in the present research. As noted, it is to be expected that these correlations are lower for state emotions (Goetz, 2004; Goetz et al., 2007), which would further underscore the need to distinguish between discrete achievement emotions.

Furthermore, the findings regarding external validity are lim ited by the correlational nature of the study design which does not allow to interpret linkages between emotions, appraisals, and learning in causal ways. There are a few studies that in cluded selected scales of the AEQ and used predictive designs. These studies suggest that the AEQ scales have predictive power in explaining students' achievement outcomes, and that the emotions assessed by the AEQ scales are explained by students goals and appraisals (Daniels et al., 2009; Pekrun et al., 2009, 2010). However, more research is clearly needed to disentangle the causal relationships of achievement emotions with their antecedents and outcomes. Beyond unidirectional, predictive de signs, such research should also attend to the reciprocal nature of these linkages. For example, appraisals can induce achieve ment emotions, but these emotions can reciprocally influence students' appraisals and adoption of achievement goals (Daniels et al., 2009; Linnenbrink \& Pintrich, 2002). Similarly, achieve ment emotions can impact students' success at learning, but suc cess and failure can reciprocally shape students' emotions (Pekrun, 2006).

Finally, the present findings have a number of important implications for educational practice. First, they suggest that the AEQ can be used to assess students' achievement emotions. To date, the instrument has mainly been employed for research purposes, but it also may be well suited to serve practical pur poses for assessment in counseling and evaluation. Given the overall length of the instrument, this may require further re search to tailor the scales to the specific purposes within given diagnostic settings. Also, research would be needed to norm the scales for practical application. Second, although caution should be given to not interpreting the findings in causal ways, they are clearly in line with the assumption that a number of different emotions are of critical importance to students' engagement and learning. By implication, educators are well advised to heed stu dents' emotions including the well researched emotion test anx iety, but also including a broad variety of emotions beyond anxiety.

\section{Acknowledgments}

This research was supported by a TransCoop grant entitled "Academic Risk Factors in College Students" from the German American Academic Council to Reinhard Pekrun and Raymond P. Perry, and by a grant from the German Research Foundation (Deut sche Forschungsgemeinschaft, DFG) entitled "Lern und Prüfung semotionen" [Learning related and test related emotions] to Reinhard Pekrun. 


\section{Appendix A}

Achievement Emotions Questionnaire (AEQ): scales and sample items.

\begin{tabular}{|c|c|}
\hline \multicolumn{2}{|c|}{ Class related emotions } \\
\hline 1 Enjoyment & I enjoy being in class (d) \\
\hline 2 Hope & I am confident when I go to class (b) \\
\hline 3 Pride & I am proud of myself (a) \\
\hline 4 Anger & I am angry (a) \\
\hline 5 Anxiety & Thinking about class makes me feel uneasy (b) \\
\hline 6 Shame & I get embarrassed $(\mathrm{d})$ \\
\hline 7 Hopelessness & I feel hopeless (b) \\
\hline 8 Boredom & I get bored $(\mathrm{d})$ \\
\hline \multicolumn{2}{|c|}{ Learning related emotions } \\
\hline 1 Enjoyment & I enjoy acquiring new knowledge (d) \\
\hline 2 Hope & I have an optimistic view toward studying (b) \\
\hline 3 Pride & I'm proud of my capacity (d) \\
\hline 4 Anger & Studying makes me irritated (d) \\
\hline 5 Anxiety & I get tense and nervous while studying (d) \\
\hline 6 Shame & $\begin{array}{l}\text { I feel ashamed that I can't absorb the simplest } \\
\text { of details (d) }\end{array}$ \\
\hline 7 Hopelessness & I feel hopeless when I think about studying (b) \\
\hline & The material bores me to death (d) \\
\hline \multicolumn{2}{|l|}{ Test emotions } \\
\hline 1 Enjoyment & For me the test is a challenge that is enjoyable (d) \\
\hline 2 Hope & $\begin{array}{l}\text { I have great hope that my abilities will be suffi } \\
\text { cient (b) }\end{array}$ \\
\hline 3 Pride & I'm proud of how well I mastered the exam (a) \\
\hline 4 Relief & I feel very relieved (a) \\
\hline 5 Anger & I am fairly annoyed (a) \\
\hline 6 Anxiety & I feel panicky when writing an exam (d) \\
\hline 7 Shame & I feel ashamed (a) \\
\hline 8 Hopelessness & $\begin{array}{l}\text { I have lost all hope that I have the ability to do } \\
\text { well on the exam (d) }\end{array}$ \\
\hline
\end{tabular}

Note: $\mathrm{b} / \mathrm{d} / \mathrm{a}=$ before/during/after the situation of attending class, studying, or taking tests and exams, respectively.

\section{References}

Acee, T. W., Kim, H., Kim, H. J., Kim, J., Hsiang-Ning, R. C., Kim, M., et al. (2010). Academic boredom in under- and overchallenging situations. Contemporary Educational Psychology, 35, 17-27.

Bandura, A. (1977). Self-efficacy: Toward a unifying theory of behavioral change. Psychological Review, 84, 191-215.

Boekaerts, M. (1993). Anger in relation to school learning. Learning and Instruction, 3, 269-280.

Daniels, L. M., Stupnisky, R. H., Pekrun, R., Haynes, T. L., Perry, R. P., \& Newall, N. E. (2009). A longitudinal analysis of achievement goals: From affective antecedents to emotional effects and achievement outcomes. Journal of Educational Psychology, 101, 948-963.

Endler, N., \& Okada, M. (1975). A multidimensional measure of trait anxiety: The S$\mathrm{R}$ Inventory of General Trait Anxiousness. Journal of Consulting and Clinical Psychology, 43, 319-329.

Feldman Barrett, L., \& Russell, J. A. (1998). Independence and bipolarity in the structure of current affect. Journal of Personality and Social Psychology, 74. 967-984.

Fredrickson, B. L. (2001). The role of positive emotions in positive psychology: The broaden-and-build theory of positive emotions. American Psychologist, 56, 218-226.

Frenzel, A. C., Pekrun, R., \& Goetz, T. (2007). Girls and mathematics - a "hopeless" issue? A control-value approach to gender differences in emotions towards mathematics. European Journal of Psychology of Education, 22, 497-514.

Frenzel, A. C., Thrash, T. M., Pekrun, R., \& Goetz, T. (2007). Achievement emotions in Germany and China: A cross-cultural validation of the Academic Emotions Questionnaire-Mathematics (AEQ-M). Journal of Cross-Cultural Psychology, 38, 302-309.
Goetz, T. (2004). Emotionales Erleben und selbsreguliertes Lernen bei Schülern im Fach Mathematik [Students' emotions and self-regulated learning in mathematics]. München, Germany: Utz

Goetz, T., Frenzel, A. C., Pekrun, R., Hall, N. C., \& Lüdtke, O. (2007). Between- and within-domain relations of students' academic emotions. Journal of Educational Psychology, 99, 715-733.

Goetz, T., Preckel, F., Pekrun, R., \& Hall, N. C. (2007). Emotional experiences during test taking: Does cognitive ability make a difference? Learning and Individual Differences, $17,3-16$

Hembree, R. (1988). Correlates, causes, effects, and treatment of test anxiety. Review of Educational Research, 58, 47-77.

Hodapp, V., \& Benson, J. (1997). The multidimensionality of test anxiety: A test of different models. Anxiety, Stress and Coping, 10, 219-244.

Hoyle, R., \& Panter, A. (1995). Writing about structural equation models. In R. Hoyle (Ed.). Structural equation modeling: Concepts, issues, and applications (pp. 100-119). Thousand Oaks, CA: Sage.

Jöreskog, K. G., \& Sörbom, D. (2006). LISREL 8.80 for Windows [Computer Software]. Lincolnwood, IL: Scientific Software International, Inc.

Karabenick, S. A., Woolley, M. E., Friedel, J. M., Ammon, B. V., Blazevski, J., Ree Bonney, C., et al. (2007). Cognitive processing of self-report items in educational research: Do they think what we mean? Educational Psychologist, 42, 139-151.

Kuppens, P., van Mechelen, I., Smits, D. J. M., \& de Boeck, P. (2004). Association between emotions: Correspondence across different types of data and componential basis. European Journal of Personality, 18, 159-176.

Lane, A. M., Whyte, G. P., Terry, P. C., \& Nevill, A. M. (2005). Mood, self-set goals and examination performance: The moderating effect of depressed mood. Personality and Individual Differences, 39, 143-153.

Lazarus, R. S., \& Folkman, S. (1984). Stress, appraisal, and coping. New York: Springer

Lichtenfeld, S., Pekrun, R., Stupnisky, R. H., Reiss, K., \& Murayama, K. (2010). Measuring students' emotions in the early years: The Achievement Emotions Questionnaire-Elementary School ( $A E Q-E)$, submitted for publication.

Linnenbrink, E. A. (2007). The role of affect in student learning: A multi-dimensional approach to considering the interaction of affect, motivation, and engagement. In P. A. Schutz \& R. Pekrun (Eds.), Emotion in education (pp. 107-124). San Diego, CA: Academic Press.

Linnenbrink, E. A., \& Pintrich, P. R. (2002). Achievement goal theory and affect: An asymmetrical bidirectional model. Educational Psychologist, 37, 69-78.

Mandler, G., \& Sarason, S. B. (1952). A study of anxiety and learning. Journal of Abnormal and Social Psychology. 47, 166-173.

Marsh, H. W., Byrne, B. W., \& Craven, R. (1993). Overcoming problems in confirmatory factor analyses of MTMM data: The correlated uniqueness model and factorial invariance. Multivariate Behavioral Research, 27, 489-507.

Mouratidis, A., Vansteenkiste, M., Lens, W., \& Auweele, Y. V. (2009). Beyond positive and negative affect: Achievement goals and discrete emotions in the elementary physical education classroom. Psychology of Sport and Exercise, 10. 336-343.

Pekrun, R. (1992a). Expectancy-value theory of anxiety: Overview and implications. In D. G. Forgays, T. Sosnowski, \& K. Wrzesniewski (Eds.), Anxiety: Recent developments in self-appraisal, psychophysiological and health research (pp. 23-41). Washington, DC: Hemisphere.

Pekrun, R. (1992b). The impact of emotions on learning and achievement: Towards a theory of cognitive/motivational mediators. Applied Psychology, 41, 359-376.

Pekrun, R. (1992c). Kognition und Emotion in studienbezogenen Lern- und Leistungssituationen: Explorative Analysen [Cognition and emotion in academic situations of learning and achievement: An exploratory analysis]. Unterrichtswissenschaft, 20,308-324

Pekrun, R. (2006). The control-value theory of achievement emotions: Assumptions, corollaries, and implications for educational research and practice. Educational Psychology Review, 18, 315-341.

Pekrun, R., Elliot, A. J.. \& Maier, M. A. (2006). Achievement goals and discrete achievement emotions: A theoretical model and prospective test. Journal of Educational Psychology, 98, 583-597.

Pekrun, R., Elliot, A. J., \& Maier, M. A. (2009). Achievement goals and achievement emotions: Testing a model of their joint relations with academic performance. Journal of Educational Psychology, 101, 115-135.

Pekrun, R. Goetz, T. Frenzel, A. C. \& Perry, R. P. (2011). Academic Emotions Questionnaire (AEQ). User's manual (2nd ed.). Munich, Germany: Department of Psychology, University of Munich.

Pekrun, R., Frenzel, A., Goetz, T., \& Perry, R. P. (2007). The control-value theory of achievement emotions: An integrative approach to emotions in education. In P. A. Schutz \& R. Pekrun (Eds.), Emotions in education (pp. 13-36). San Diego: Academic Press.

Pekrun, R., Goetz, T., Daniels, L. M., Stupnisky, R. H., \& Perry, R. P. (2010). Boredom in achievement settings: Exploring control-value antecedents and performance outcomes of a neglected emotion. Journal of Educational Psychology, 102, 531-549.

Pekrun, R., Goetz, T., Perry, R. P., Kramer, K., \& Hochstadt, M. (2004). Beyond test anxiety: Development and validation of the Test Emotions Questionnaire (TEQ). Anxiety, Stress and Coping, 17, 287-316.

Pekrun, R., Goetz, T., Titz, W., \& Perry, R. P. (2002). Academic emotions in students' self-regulated learning and achievement: A program of quantitative and qualitative research. Educational Psychologist, 37, 91-106.

Perry, R. P., Hladkyj, S., Pekrun, R., \& Pelletier, S. T. (2001). Academic control and action control in the achievement of college students: A longitudinal field study. Journal of Educational Psychology, 93, 776-789. 
Perry, R. P., Stupnisky, R. H., Hall, N. C., Chipperfield, J. G., \& Weiner, B. (2010). Bad starts and better finishes: Attributional retraining and initial performance in competitive achievement settings. Journal of Social and Clinical Psychology, 29. competitive

Pintrich, P. R., Smith, D. A. F., Garcia, T., \& McKeachie, W. J. (1991). A manual for the use of the Motivated Strategies for Learning Questionnaire (MSLO) (Tech. Repor No. 91-B-004). Board of Regents, University of Michigan, Ann Arbor, MI.

Sarason, I. G. (1984). Stress, anxiety, and cognitive interference: Reactions to tests. Journal of Personality and Social Psychology, 44, 929-938.

Schutz, P. A., \& Pekrun, R. (Eds.). (2007). Emotion in education. San Diego, CA: Academic Press.

Scherer, K. R. (2009). The dynamic architecture of emotion: Evidence for the component process model. Cognition and Emotion, 23, 1307-1351.

Skinner, E. A. (1996). A guide to constructs of control. Journal of Personality and Social Psychology, 71, 549-570.

Slaney, K. L., \& Maraun, M. D. (2008). A proposed framework for conducting databased test analysis. Psychological Methods, 13, 376-390.

Spangler, G., Pekrun, R., Kramer, K., \& Hofmann, H. (2002). Students' emotions, physiological reactions, and coping in academic exams. Anxiety, Stress and Coping, 15, 383-400.
Spielberger, C. D., Anton, W. D., \& Bedell, J. (1976). The nature and treatment of test anxiety. In M. Zuckerman \& C. D. Spielberger (Eds.), Emotions and anxiety: New concepts, methods, and applications (pp. 317-344). Hillsdale, NJ: Erlbaum.

Titz, W. (2001). Emotionen von Studierenden in Lernsituationen [Students' emotions in situations of learningl. Münster, Germany: Waxmann.

Turner, J. E., \& Schallert, D. L. (2001). Expectancy-value relationships of shame reactions and shame resiliency. Journal of Educational Psychology, 93, 320329.

Watson, D., \& Clark, L. A. (1992). Affects separable and inseparable: On the hierarchical arrangement of the negative affects. Journal of Personality and Social Psychology, 62, 489-505.

Weiner, B. (1985). An attributional theory of achievement motivation and emotion. Psychological Review, 92, 548-573.

Zeidner, M. (1998). Test anxiety: The state of the art. New York: Plenum.

Zeidner, M. (2007). Test anxiety in educational contexts: What I have learned so far. In P. A. Schutz \& R. Pekrun (Eds.), Emotion in education (pp. 165-184). San Diego, CA: Academic Press. 